\title{
Impact of fan therapy during exercise on breathlessness and recovery time in patients with COPD: a pilot randomised controlled crossover trial
}

\author{
Alex Long ${ }^{1,2}$, Martin Cartwright ${ }^{2}$ and Charles C. Reilly $\mathbb{C}^{1,3}$
}

${ }^{1}$ Dept of Physiotherapy, King's College Hospital NHS Foundation Trust, London, UK. ${ }^{2}$ School of Health Sciences, City, University of London, London, UK. ${ }^{3}$ Cicely Saunders Institute of Palliative Care, Policy and Rehabilitation, King's College London, London, UK.

Corresponding author: Charles C. Reilly (charles.c.reilly@kcl.ac.uk)

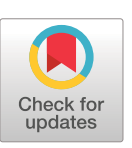

Copyright @The authors 2021

This version is distributed under the terms of the Creative Commons Attribution NonCommercial Licence 4.0. For commercial reproduction rights and permissions contact permissions@ersnet.org

Received: 24 March 2021 Accepted: 10 Aug 2021

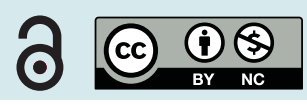

\begin{abstract}
Shareable abstract (@ERSpublications)
Fan therapy was acceptable and provided symptomatic relief to patients with COPD during exercise; these positive preliminary findings suggest that fan therapy merits further investigation in larger and more methodologically rigorous studies https://bit.ly/3xR2GDW
\end{abstract}

Cite this article as: Long A, Cartwright M, Reilly CC. Impact of fan therapy during exercise on breathlessness and recovery time in patients with COPD: a pilot randomised controlled crossover trial. ERJ Open Res 2021; 7: 00211-2021 [DOI: 10.1183/23120541.00211-2021].

\section{Abstract}

Background Patients with COPD reduce physical activity to avoid the onset of breathlessness. Fan therapy can reduce breathlessness at rest, but the efficacy of fan therapy during exercise remains unknown in this population. The aim of the present study was to investigate 1) the effect of fan therapy on exercise-induced breathlessness and post-exercise recovery time in patients with COPD and 2) the acceptability of fan therapy during exercise; and 3) to assess the reproducibility of any observed improvements in outcome measures.

Methods A pilot single-centre, randomised, controlled, crossover open (nonmasked) trial (clinicaltrials.gov NCT03137524) of fan therapy versus no fan therapy during 6-min walk test (6MWT) in patients with COPD and a modified Medical Research Council (mMRC) dyspnoea score $\geqslant 2$. Breathlessness intensity was quantified before and on termination of the 6MWT, using the numerical rating scale (NRS) (0-10). Post-exertional recovery time was measured, defined as the time taken to return to baseline NRS breathlessness score. Oxygen saturation and heart rate were measure pre- and post-6MWT.

Results 14 patients with COPD completed the trial per protocol (four male, 10 female; median (interquartile range (IQR)) age 66.50 (60.75 to 73.50) years); mMRC dyspnoea 3 (2 to 3)). Fan therapy resulted in lower exercise-induced breathlessness ( $\triangle \mathrm{NRS} ; \Delta$ modified Borg scale) (within-individual differences in medians (WIDiM) -1.00 , IQR -2.00 to -0.50 ; $\mathrm{p}<0.01$; WIDiM -0.25 , IQR -2.00 to 0.00 ; $\mathrm{p}=0.02$ ), greater distance walked (metres) during the 6MWT (WIDiM 21.25, IQR 12.75 to 31.88; $<<0.01$ ), and improved post-exertional breathlessness (NRS) recovery time (WIDiM -10.00 , IQR -78.75 to 50.00; $\mathrm{p}<0.01)$. Fan therapy was deemed to be acceptable by $92 \%$ of participants.

Conclusion Fan therapy was acceptable and provided symptomatic relief to patients with COPD during exercise. These data will inform larger pilot studies and efficacy studies of fan therapy during exercise.

\section{Introduction}

COPD is defined as "a common and treatable disease characterised by persistent respiratory symptoms and airflow limitation that is due to airway and/or alveolar abnormalities usually caused by significant exposure to noxious particles or gas” [1]. COPD is progressive, associated with frequent exacerbation of symptoms including increased breathlessness, leading to increased disability and reduced quality of life [1].

COPD is the fourth leading cause of death worldwide [2]. Over a million individuals in the United Kingdom (UK) have COPD, resulting in $>25000$ deaths each year due to COPD [3]. COPD mortality in the UK is third in Europe [3]. 
The burden of chronic breathlessness is significant for patients with COPD, negatively impacting upon health-related quality of life and physical function, as patients frequently avoid activities that evoke breathlessness. This fear-avoidance results in disuse atrophy, which perpetuates a cycle of increasing breathlessness and disability $[4,5]$.

Exercise interventions such as pulmonary rehabilitation for patients with COPD improve breathlessness and physical function and reduce exacerbation frequency and hospital admission [6]. However, pulmonary rehabilitation is a brief intervention and maintaining these benefits requires patients to continue to exercise independently. Breathlessness is the main limiting factor to exercise in COPD [7]; therefore, any interventions to help patients to self-manage their exercise-induced breathlessness are sought.

Evidence suggests that cool facial airflow from either medical air (room air delivered under pressure via a concentrator or canister) or a fan can reduce breathlessness at rest [8, 9]. The burden of chronic breathlessness is significant for patients with COPD, and their families [10, 11]. Holistic breathlessness support services have been shown to improve breathlessness mastery and reduce distress due to breathlessness, where fan therapy is an integral part of these self-management interventions [12, 13]. Moreover, qualitative data from patients with chronic breathlessness describe improvements in their ability to control their breathlessness at rest (self-mastery) with the use of fan therapy [12]. The efficacy and acceptability of fan therapy during exercise remains unknown in patients with COPD.

The aim of this study was 1) to investigate the effect of fan therapy on exercise-induced breathlessness and post-exercise recovery time in patients with COPD; 2) to investigate the acceptability of fan therapy during exercise; and 3) to assess the reproducibility of any observed improvements in outcome measures.

We hypothesised that fan therapy would reduce exercise-induced breathlessness and improve post-exercise recovery time in patients with COPD. (Null hypothesis: there would be no difference in exercise-induced breathlessness, physiological variables, e.g. heart rate, oxygen saturation or recovery time when assessed in the fan therapy and no fan therapy conditions for a 6-min walk test (6MWT).)

Methods

Design

A pilot single-centre randomised controlled crossover, open (nonmasked) trial (NCT03137524) of fan therapy versus no fan therapy during 6MWT in patients with COPD and modified Medical Research Council (mMRC) dyspnoea score $\geqslant 2$. There was a 30-min washout period between 6MWTs (figure 1).

\section{Participants}

Inclusion criteria: adults with a diagnosis of COPD by a respiratory physician (characterised by forced expiratory volume in $1 \mathrm{~s}\left(\mathrm{FEV}_{1}\right)$ /forced vital capacity ratio $\leqslant 70 \%$ ), with exertional breathlessness (mMRC dyspnoea score $\geqslant 2$ ) and a stable smoking status were eligible.

Exclusion criteria: significant cardiovascular or peripheral disease that could influence exercise tolerance, recent change in medication or exacerbation of COPD symptoms requiring admission during the preceding 4 weeks; unable to hold a handheld fan; unable to speak English; or not capable of providing informed consent.

\section{Recruitment}

Patients were recruited from specialist COPD outpatient clinics and Pulmonary Rehabilitation at King's College Hospital NHS Foundation Trust (KCH) (Denmark Hill site, London, UK). Participants fulfilling eligibility criteria were recruited by convenience sampling. Potential participants were identified by members of the clinical teams, who gained consent for their contact details to be passed on to the researcher. Thereafter, participants were sent by post an invitation to participate and an information letter from the researcher, given $\geqslant 1$ week to read thoroughly, then re-contacted by the researcher to discuss any concerns. Interest in the study led to an assessment date being organised, at which consent forms were signed.

\section{Randomisation and masking}

Block randomisation was implemented using an online tool (www.sealedenvelope.com/simple-randomiser/ $\mathrm{v1/)}$ to allocate participants to their initial experimental conditions (i.e. walking with a hand-held fan versus walking without a fan) and ensure the conditions were numerically balanced. Simple four-block randomisation was applied. On completion of the initial walking test and outcome assessments, 


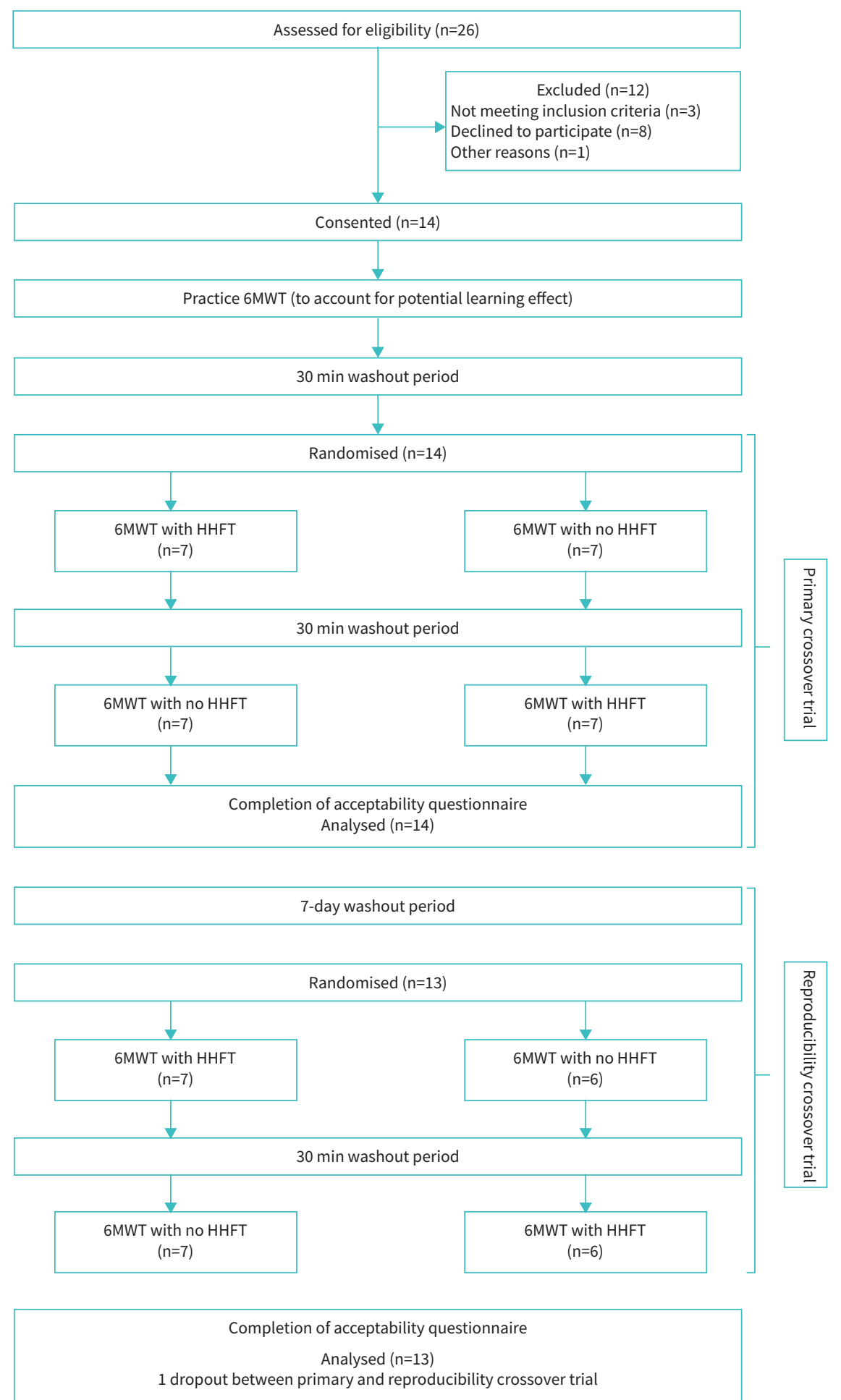

FIGURE 1 Study design and flow of patient through the study protocol: a pilot single-centre randomised controlled crossover open (nonmasked) trial of hand-held fan therapy (HHFT) versus no HHFT during 6-min walk test (6MWT) in patients with COPD and modified Medical Research Council dyspnoea score $\geqslant 2$.

participants were given 30 min to recover physiologically and then they repeated the walking test in the alternative experimental condition. Due to the nature of the intervention (fan therapy), it was not possible to blind the researcher or patients to the allocations. 
Sample size

No formal sample size calculation was performed, due to the lack of data regarding the potential impact fan therapy may have on exercise-induced breathlessness in COPD. Therefore, this pilot study aimed to recruit 14-16 participants. The pilot data will inform subsequent efficacy studies of fan therapy during exercise.

\section{Ethical approval}

Ethical and local research and development approval (KCH17-062) was obtained prior to commencing this research (LREC protocol number: REC 17/NE/0063). The study was registered on www.clinicaltrials. gov (NCT03137524). All participants provided written informed consent.

\section{Intervention: fan therapy}

The handheld fans used were commercially available and battery-operated, with three soft propeller blades and an on/off switch usable by participants (Marks and Spencer's Pocket-Sized Travel Fan, cost per fan GBP 6.00). Patients were provided with standardised instructions as how to use the handheld fan: to hold the fan to their face throughout both the walking test and during the recovery period until they reported that breathlessness returned to baseline.

\section{Primary outcome measure}

Breathlessness change: the magnitude of exercise-induced breathlessness during a 6MWT, defined as the change $(\Delta)$ in breathlessness scores from rest (immediately pre-exercise) to immediately post-exercise, quantified using the numerical rating scale (NRS). The NRS breathlessness is a validated, self-reported, unidimensional scale to rate chronic breathlessness intensity. It is simple to use across a variety of everyday activities, and adjustable to specific time points [14]. NRS anchors were $0=$ not breathless at all, $10=$ worst possible breathlessness.

\section{Secondary outcome measures}

Breathlessness intensity

Self-reported level or intensity of breathlessness as indicated on the NRS.

\section{Perceived breathing difficulty/effort}

Perceived breathing difficulty/effort was quantified using the modified Borg breathlessness (mBorg) scale at rest and at end exercise. The mBorg is quantifies perceived breathing difficulty/effort on a $0-10$ scale, with descriptors, e.g. $0=$ none at all, 5=severe, $10=$ maximal. It was developed for use during exertion [15]. It has a minimal clinically important difference (MCID) of 1 point, with larger changes more likely at the higher end of the scale due to larger numerical intervals between descriptive markers [16]. Reliability and validity of mBorg breathlessness measurement during 6MWT is accepted (intraclass correlation coefficient from 0.59 to 0.92 ; mean difference of $<1$ point) [17].

\section{Distance walked $(m)$ during the 6MWT}

The 6MWT is a self-paced walking test. It measures walking capacity by measuring total distance covered around a flat $30-\mathrm{m}$ course in $6 \mathrm{~min}$. Standardised instructions are given throughout the test. It is a robust test of functional exercise capacity [17].

\section{Post-exertional recovery time (s)}

Post-exertional recovery time was measured, defined as the time taken to return to baseline NRS breathlessness score, peripheral oxygen saturation $\left(S_{\mathrm{pO}_{2}}\right)$ and heart rate. Participants were asked to report when their NRS breathlessness score had returned to base levels. $S_{\mathrm{pO}_{2}}$ and heart rate were measured using a pulse oximetry (Onyx 9500 Fingertip Pulse Oximeter; Nonin Medical, Plymouth, MN, USA). $S_{\mathrm{pO}_{2}}$ and heart rate were measured at rest, during and post-6MWT.

\section{Acceptability of using the handheld fan}

Acceptability was assessed via a Likert scale questionnaire (range 1-5) based on the theoretical framework of acceptability (TFA) [18]. Participants were asked to respond to specific questions reflecting the overall acceptability of fan therapy and five subconstructs from the TFA (affective attitude, burden, perceived effectiveness, intervention coherence and self-efficacy).

\section{Experimental protocol}

The study was conducted at the clinical research facility at $\mathrm{KCH}$. Baseline demographic data included age, sex, spirometry, smoking history, body mass index, mMRC dyspnoea score, COPD Assessment Test (CAT). 
Participants performed three 6MWTs: one for practice, to account for potential learning effect, followed by two as per protocol (figure 1). The 6MWT was performed in accordance with technical procedures described by the American Thoracic Society [19]. Participants were given a 30-min period between the practice 6MWT and commencing the crossover trial experimental protocol (figure 1). Outcome measures recorded pre and post all 6MWTs included NRS breathlessness, mBorg, heart rate and $S_{\mathrm{pO}_{2}}$. The distance walked and number of rest periods/stops the patient required was recorded for all 6MWTs completed. Recovery time for NRS and heart rate to return to baseline post-6MWT was timed (in seconds) immediately from the end of the 6MWT. Recovery was recorded in standardised seated position. The self-reported acceptability questionnaire was completed at the end of the crossover trial (figure 1).

\section{Reproducibility}

To assess the reproducibility/consistency of any observed improvements in outcome measures, patients were invited to complete the experimental protocol again, a week later (trial 2). To reduce the chance of any imbalances between allocation sequence groups ( $\mathrm{AB}$ versus $\mathrm{BA}$ ) following the initial randomisation in trial 1 being carried forward to trial 2, participants were re-randomised to allocation sequences for trial 2.

\section{Data analysis and reporting}

Inferential statistical analysis of outcomes was completed, with a significance level of $\mathrm{p}<0.05$ using the statistical package SPSS v26 (IBM, Armonk, NY, USA). Normality of the data was determined by skewness and Shapiro-Wilk test. The data was non-normally distributed, hence central tendencies are described using medians and interquartile ranges (IQRs) calculated in Microsoft Excel (version 2016). Within-individual differences in the medians (WIDiMs) and IQRs (fan versus no fan) were calculated by first subtracting a participant's score in the no fan condition from their score in the fan condition, and then calculating the median (IQR) of these within-individual differences. WIDiMs retain the repeated nature of the crossover design at the level of the individual and are used to assess treatment effects [20], in our case using nonparametric tests (Wilcoxon matched-pairs signed-rank tests, with two-sided exact significance). In addition, in tables 2 and 3, group-level medians are reported. For example, for participants allocated to the sequence fan-then-no-fan $(n=7)$, we report the group-level medians for each outcome in the fan condition and in the no-fan condition. These group-level medians do not retain the repeated nature of the crossover design at the level of the individual, so they cannot legitimately be used to estimate treatment effects; however, they are helpful in understanding the likelihood of carryover effects and period (order) effects, as well as the amount of missing data [20]. WIDiMs and group-level medians are not directly related, as they are generated from independent calculations.

\section{Results}

\section{Recruitment and engagement}

Recruitment took place over 10 weeks (May to July 2017). 26 patients were screened; three (12\%) were ineligible. Of the 23 eligible patients, eight (35\%) declined to participate and 14 (61\%) agreed to participate and were randomised. 14 participants (100\%) completed the trial per protocol (table 1). 13

TABLE 1 Patient characteristics of the 14 patients who completed the randomised controlled crossover trial of fan therapy versus no fan therapy during 6-min walk test

\begin{tabular}{|c|c|}
\hline Age (years) & $66.50(60.75-73.50)$ \\
\hline BMI $\left(\mathrm{kg} \cdot \mathrm{m}^{-2}\right)$ & $25.85(20.60-30.25)$ \\
\hline Male/female & $4 / 10$ \\
\hline \multicolumn{2}{|l|}{ Smoking status } \\
\hline Current smoker & 6 \\
\hline Ex-smoker & 8 \\
\hline Smoking (pack-years) & $48.00(25.75-82.60)$ \\
\hline mMRC dyspnoea score & $3.00(2.00-3.00)$ \\
\hline $\mathrm{FEV}_{1}(\mathrm{~L})$ & $1.30(0.94-1.59)$ \\
\hline FEV $_{1}(\%)$ & $63.00(38.75-74.0)$ \\
\hline FVC (L) & 2.30 (1.90-2.75) \\
\hline FVC (\%) & $82.00(71.00-93.25)$ \\
\hline $\mathrm{FEV}_{1} / \mathrm{FVC}$ ratio & $56.75(47.43-63.50)$ \\
\hline CAT score & $21.00(12.25-29.75)$ \\
\hline
\end{tabular}


TABLE 2 Results observed in the primary randomised controlled crossover trial of fan therapy versus no fan therapy during 6-min walk test (6MWT) in patients with COPD

\begin{tabular}{|c|c|c|c|c|c|c|c|c|c|c|}
\hline & \multicolumn{4}{|c|}{ Allocation sequence $A B$ (fan/no fan) } & \multicolumn{4}{|c|}{ Allocation sequence BA (no fan/fan) } & \multirow{2}{*}{\multicolumn{2}{|c|}{$\begin{array}{c}\text { Overall treatment } \\
\text { effect }\end{array}$}} \\
\hline & \multicolumn{2}{|c|}{$\begin{array}{l}\text { Group-level median } \\
\text { (IQR) }\end{array}$} & \multicolumn{2}{|c|}{ WIDiM (IQR) } & \multicolumn{2}{|c|}{$\begin{array}{l}\text { Group-level median } \\
\text { (IQR) }\end{array}$} & \multicolumn{2}{|c|}{ WIDiM (IQR) } & & \\
\hline & $\begin{array}{l}\text { Period } 1 \\
\text { fan }\end{array}$ & $\begin{array}{l}\text { Period } 2 \\
\text { no fan }\end{array}$ & WIDiM $^{\#}$ & $\begin{array}{l}\text { Wilcoxon } \\
\text { signed } \\
\text { rank test }^{q}\end{array}$ & $\begin{array}{l}\text { Period } 1 \\
\text { no fan }\end{array}$ & $\begin{array}{l}\text { Period } 2 \\
\quad \text { fan }\end{array}$ & WIDiM $^{\#}$ & $\begin{array}{l}\text { Wilcoxon } \\
\text { signed } \\
\text { rank test }\end{array}$ & WIDiM $^{\#}$ & $\begin{array}{l}\text { Wilcoxon } \\
\text { signed } \\
\text { rank test }\end{array}$ \\
\hline Patients (n) & 7 & 7 & 7 & & 6 & 6 & 6 & & 13 & \\
\hline \multicolumn{11}{|l|}{$\begin{array}{l}\text { Subjective } \\
\text { measures of } \\
\text { breathlessness }\end{array}$} \\
\hline $\mathrm{NRS}^{+}$ & $\begin{array}{c}5.00 \\
(3.75 \text { to } \\
6.25)\end{array}$ & $\begin{array}{c}7.00 \\
(6.25 \text { to } \\
8.25)\end{array}$ & $\begin{array}{c}-2.00 \\
(-2.00 \text { to } \\
-1.00)\end{array}$ & 0.02 & $\begin{array}{c}4.00 \\
(2.50 \text { to } \\
5.75)\end{array}$ & $\begin{array}{c}3.00 \\
(2.00 \text { to } \\
4.75)\end{array}$ & $\begin{array}{c}-0.50 \\
(-1.25 \\
\text { to } 0.00)\end{array}$ & 0.25 & $\begin{array}{c}-1.00 \\
(-2.00 \text { to } \\
-0.50)\end{array}$ & $<0.01$ \\
\hline$\Delta \mathrm{NRS}^{\S}$ & $\begin{array}{c}3.00 \\
(1.25 \text { to } \\
4.25)\end{array}$ & $\begin{array}{c}5.00 \\
(3.00 \text { to } \\
6.75)\end{array}$ & $\begin{array}{l}-1.50 \\
(-2.00 \text { to } \\
-1.00)\end{array}$ & 0.02 & $\begin{array}{c}3.50 \\
(2.25 \text { to } \\
4.75)\end{array}$ & $\begin{array}{c}3.00 \\
(1.75 \text { to } \\
3.25)\end{array}$ & $\begin{array}{r}-0.50 \\
(-1.25 \\
\text { to } 0.00)\end{array}$ & 0.25 & $\begin{array}{c}-1.00 \\
(-2.00 \text { to } \\
-0.50)\end{array}$ & $<0.01$ \\
\hline $\begin{array}{l}\text { NRS recovery } \\
\text { time }^{+}\end{array}$ & $\begin{array}{c}110.00 \\
(15.00 \text { to } \\
135.00)\end{array}$ & $\begin{array}{l}210.00 \\
(160.00 \\
\text { to } \\
295.00)\end{array}$ & $\begin{array}{c}-90.00 \\
(-205.00 \\
\text { to }-32.50)\end{array}$ & 0.03 & $\begin{array}{c}150.00 \\
(75.00 \text { to } \\
195.00)\end{array}$ & $\begin{array}{l}210.00 \\
(165.00 \\
\text { to } \\
227.50)\end{array}$ & $\begin{array}{c}60.00 \\
(10.00 \text { to } \\
65.00)\end{array}$ & 0.09 & $\begin{array}{c}-10.00 \\
(-78.75 \\
\text { to } 50.00)\end{array}$ & $<0.01$ \\
\hline $\mathrm{mBorg}^{+}$ & $\begin{array}{c}3.00 \\
(0.75 \text { to } \\
3.50)\end{array}$ & $\begin{array}{c}4.00 \\
(4.00 \text { to } \\
5.00)\end{array}$ & $\begin{array}{c}-1.00 \\
(-2.50 \text { to } \\
0.25)\end{array}$ & 0.06 & $\begin{array}{c}3.00 \\
(2.00 \text { to } \\
4.50)\end{array}$ & $\begin{array}{c}3.00 \\
(1.00 \text { to } \\
3.50)\end{array}$ & $\begin{array}{c}0.00 \\
(-1.00 \\
\text { to } 0.00)\end{array}$ & 0.50 & $\begin{array}{c}-0.25 \\
(-2.00 \text { to } \\
0.00)\end{array}$ & 0.02 \\
\hline$\Delta \mathrm{mBorg}{ }^{\S}$ & $\begin{array}{c}2.00 \\
(0.25 \text { to } \\
3.00)\end{array}$ & $\begin{array}{c}3.50 \\
(3.50 \text { to } \\
4.00)\end{array}$ & $\begin{array}{c}-1.00 \\
(-2.50 \text { to } \\
-0.25)\end{array}$ & 0.06 & $\begin{array}{c}3.00 \\
(1.75 \text { to } \\
3.50)\end{array}$ & $\begin{array}{c}2.00 \\
(0.75 \text { to } \\
3.00)\end{array}$ & $\begin{array}{c}0.00 \\
(-1.00 \\
\text { to } 0.00)\end{array}$ & 0.50 & $\begin{array}{c}-0.25 \\
(-2.00 \\
0.00)\end{array}$ & 0.02 \\
\hline \multicolumn{11}{|l|}{$\begin{array}{l}\text { Objective } \\
\text { measures of } \\
\text { physiology }\end{array}$} \\
\hline $\mathrm{HR}^{+}$ & $\begin{array}{c}84.00 \\
(74.00 \text { to } \\
89.50)\end{array}$ & $\begin{array}{c}82.00 \\
(79.00 \text { to } \\
96.00)\end{array}$ & $\begin{array}{c}-4.00 \\
(-12.00 \text { to } \\
4.00)\end{array}$ & 0.38 & $\begin{array}{c}96.00 \\
(94.00 \text { to } \\
106.50)\end{array}$ & $\begin{array}{c}92.00 \\
(85.50 \text { to } \\
97.50)\end{array}$ & $\begin{array}{l}-3.00 \\
(-5.50 \\
\text { to } \\
-2.00)\end{array}$ & 0.14 & $\begin{array}{c}-3.50 \\
(-7.50 \text { to } \\
1.00)\end{array}$ & 0.11 \\
\hline$\Delta \mathrm{HR}^{\S}$ & $\begin{array}{c}11.00 \\
(5.50 \text { to } \\
14.00)\end{array}$ & $\begin{array}{c}12.00 \\
(8.50 \text { to } \\
19.00)\end{array}$ & $\begin{array}{c}-3.00 \\
(-5.50 \text { to } \\
-1.00)\end{array}$ & 0.20 & $\begin{array}{c}15.00 \\
(4.00 \text { to } \\
18.00)\end{array}$ & $\begin{array}{c}2.00 \\
(0.50 \text { to } \\
14.00)\end{array}$ & $\begin{array}{l}-3.00 \\
(-5.50 \\
\text { to } \\
-1.00)\end{array}$ & 0.47 & $\begin{array}{c}-3.00 \\
(-5.75 \text { to } \\
-0.25)\end{array}$ & 0.13 \\
\hline $\mathrm{S}_{\mathrm{pO}_{2}}{ }^{+}$ & $\begin{array}{c}96.00 \\
(94.50 \text { to } \\
98.50)\end{array}$ & $\begin{array}{c}97.00 \\
(96.50 \text { to } \\
98.00)\end{array}$ & $\begin{array}{l}0.00(-1.00 \\
\text { to } 1.00)\end{array}$ & 1.00 & $\begin{array}{c}96.00 \\
(95.00 \text { to } \\
96.50)\end{array}$ & $\begin{array}{c}97.00 \\
(95.00 \text { to } \\
97.00)\end{array}$ & $\begin{array}{c}0.00 \\
(-1.00 \\
\text { to } 1.00)\end{array}$ & 0.94 & $\begin{array}{c}0.00 \\
(-1.00 \text { to } \\
1.00)\end{array}$ & 0.70 \\
\hline$\Delta \mathrm{S}_{\mathrm{pO}_{2}}^{\S}$ & $\begin{array}{c}0.00 \\
(-1.00 \text { to } \\
1.50)\end{array}$ & $\begin{array}{c}0.00 \\
(-1.00 \text { to } \\
1.00)\end{array}$ & $\begin{array}{l}0.00(-0.50 \\
\text { to } 1.00)\end{array}$ & 1.00 & $\begin{array}{c}0.00 \\
(-1.50 \text { to } \\
0.50)\end{array}$ & $\begin{array}{c}0.00 \\
(-1.50 \text { to } \\
1.00)\end{array}$ & $\begin{array}{c}0.00 \\
(-1.00 \text { to } \\
1.00)\end{array}$ & 1.00 & $\begin{array}{c}0.00 \\
(-0.75 \text { to } \\
1.00)\end{array}$ & 1.00 \\
\hline \multicolumn{11}{|l|}{$\begin{array}{l}\text { Objective } \\
\text { measures of } \\
\text { functional } \\
\text { response }\end{array}$} \\
\hline $\begin{array}{l}\text { 6MWT distance }{ }^{f} \\
(\mathrm{~m})\end{array}$ & $\begin{array}{c}404.00 \\
(336.25 \\
\text { to } \\
465.00)\end{array}$ & $\begin{array}{l}400.00 \\
(312.50 \\
\text { to } \\
420.00)\end{array}$ & $\begin{array}{l}25.00 \\
(17.50 \text { to } \\
30.00)\end{array}$ & 0.02 & $\begin{array}{l}330.00 \\
(223.75 \\
\text { to } \\
517.50)\end{array}$ & $\begin{array}{l}383.00 \\
(247.50 \\
\text { to } \\
561.25)\end{array}$ & $\begin{array}{c}15.00 \\
(11.00 \text { to } \\
42.75)\end{array}$ & 0.02 & $\begin{array}{c}21.25 \\
(12.75 \text { to } \\
31.88)\end{array}$ & $<0.01$ \\
\hline 6MWT stops ${ }^{f}(\mathrm{n})$ & $\begin{array}{c}0.00 \\
(0.00 \text { to } \\
0.00)\end{array}$ & $\begin{array}{c}0.00 \\
(0.00 \text { to } \\
1.00)\end{array}$ & $\begin{array}{l}0.00(-0.50 \\
\text { to } 0.00)\end{array}$ & 1.00 & $\begin{array}{c}0.00 \\
(0.00 \text { to } \\
2.00)\end{array}$ & $\begin{array}{c}0.00 \\
(0.00 \text { to } \\
1.50)\end{array}$ & $\begin{array}{c}0.00 \\
(0.00 \text { to } \\
0.00)\end{array}$ & 1.000 & $\begin{array}{l}0.00(0.00 \\
\text { to } 0.00)\end{array}$ & 0.63 \\
\hline $\begin{array}{l}\text { Only within-individu } \\
\text { carryover and order } \\
\text { breathlessness; HR: } \\
\text { the fan condition ar } \\
\text { change from pre- to }\end{array}$ & $\begin{array}{l}\text { al differenc } \\
\text { effects (see } \\
\text { heart rate; } \\
\text { ad negative } \\
\text { post-exercis }\end{array}$ & $\begin{array}{l}\text { in the } \mathrm{m} \\
\text { ethods se } \\
{ }_{2} \text { : oxygen } \\
\text { lues indi } \\
{ }^{\prime}: \text { assesse }\end{array}$ & $\begin{array}{l}\text { ians (WIDiMs } \\
\text { ion). IQR: in } \\
\text { aturation me } \\
\text { e higher sc } \\
\text { during the } \epsilon\end{array}$ & $\begin{array}{l}\text { are used fo } \\
\text { quartile ra } \\
\text { ured by } p \\
\text { for the } \\
\text { rcise perio }\end{array}$ & $\begin{array}{l}\text { estimating } \\
\text { e; NRS: nu } \\
\text { e oximetry } \\
\text { fan condit }\end{array}$ & $\begin{array}{l}\text { reatment } \\
\text { nerical rati } \\
\text { \#: calculat } \\
\text { n; ^: exac }\end{array}$ & $\begin{array}{l}\text { ects; grou } \\
\text { scale; } \Delta \text { : } \\
\text { so that } \mathrm{p} \\
\text { ignificant, }\end{array}$ & $\begin{array}{l}\text { level med } \\
\text { nange; } \mathrm{mB} \\
\text { sitive valu } \\
\text { wo-tailed; }\end{array}$ & $\begin{array}{l}\text { are helpfu } \\
\text { modified } \\
\text { ndicate hig } \\
\text { ssessed pc }\end{array}$ & $\begin{array}{l}\text { in assessin } \\
\text { org scale fo } \\
\text { er scores fo } \\
\text { t-exercise; }\end{array}$ \\
\hline
\end{tabular}


TABLE 3 Results observed in the repeated randomised controlled crossover trial of fan therapy versus no fan therapy during 6-min walk test (6MWT) in patients with COPD

\begin{tabular}{|c|c|c|c|c|c|c|c|c|c|}
\hline \multicolumn{4}{|c|}{ Allocation sequence $A B$ (fan/no fan) } & \multicolumn{4}{|c|}{ Allocation sequence BA (no fan/fan) } & \multirow{2}{*}{\multicolumn{2}{|c|}{$\begin{array}{c}\text { Overall treatment effect } \\
\text { WIDiM (IQR) }\end{array}$}} \\
\hline \multicolumn{2}{|c|}{$\begin{array}{l}\text { Group-level median } \\
\text { (IQR) }\end{array}$} & \multicolumn{2}{|c|}{ WIDiM (IQR) } & \multicolumn{2}{|c|}{$\begin{array}{l}\text { Group-level median } \\
\text { (IQR) }\end{array}$} & \multicolumn{2}{|c|}{ WIDiM (IQR) } & & \\
\hline $\begin{array}{l}\text { Period } 1 \\
\text { fan }\end{array}$ & $\begin{array}{l}\text { Period } 2 \\
\text { no fan }\end{array}$ & WIDiM $^{\#}$ & $\begin{array}{l}\text { Wilcoxon } \\
\text { signed } \\
\text { rank test" }\end{array}$ & $\begin{array}{l}\text { Period } 1 \\
\text { no fan }\end{array}$ & $\begin{array}{l}\text { Period } 2 \\
\text { fan }\end{array}$ & WIDiM $^{\#}$ & $\begin{array}{l}\text { Wilcoxon } \\
\text { signed } \\
\text { rank test }\end{array}$ & WIDiM $^{\#}$ & $\begin{array}{l}\text { Wilcoxon } \\
\text { signed } \\
\text { rank test" }\end{array}$ \\
\hline
\end{tabular}

\begin{tabular}{|c|c|c|c|c|c|c|c|c|c|c|}
\hline Patients (n) & 7 & 7 & 7 & & 7 & 7 & 7 & & 13 & \\
\hline \multicolumn{11}{|l|}{$\begin{array}{l}\text { Subjective } \\
\text { measures of } \\
\text { breathlessness }\end{array}$} \\
\hline $\mathrm{NRS}^{+}$ & $\begin{array}{c}5.00 \\
(3.50 \text { to } \\
5.50)\end{array}$ & $\begin{array}{c}5.50 \\
(4.25 \text { to } \\
7.00)\end{array}$ & $\begin{array}{c}-1.00 \\
(-1.00 \text { to } \\
-0.75)\end{array}$ & 0.03 & $\begin{array}{c}3.80 \\
(0.75 \text { to } \\
6.00)\end{array}$ & $\begin{array}{c}1.80 \\
(0.38 \text { to } \\
5.00)\end{array}$ & $\begin{array}{c}-0.25 \\
(-0.88 \text { to } \\
0.00)\end{array}$ & 0.25 & $\begin{array}{c}-1.00 \\
(-1.00 \text { to } \\
0.00)\end{array}$ & $<0.01$ \\
\hline$\Delta \mathrm{NRS}^{\S}$ & $\begin{array}{c}3.50 \\
(2.25 \text { to } \\
3.75)\end{array}$ & $\begin{array}{c}4.00 \\
(2.75 \text { to } \\
4.75)\end{array}$ & $\begin{array}{c}-1.00 \\
(-1.00 \text { to } \\
-0.75)\end{array}$ & 0.03 & $\begin{array}{c}1.80 \\
(0.75 \text { to } \\
2.75)\end{array}$ & $\begin{array}{c}1.80 \\
(0.38 \text { to } \\
2.00)\end{array}$ & $\begin{array}{c}-0.25 \\
(-0.88 \text { to } \\
0.00)\end{array}$ & 0.25 & $\begin{array}{c}-1.00 \\
(-1.00 \text { to } \\
0.00)\end{array}$ & $<0.01$ \\
\hline $\begin{array}{l}\text { NRS recovery } \\
\text { time }^{+}\end{array}$ & $\begin{array}{c}120.00 \\
(75.00 \text { to } \\
180.00)\end{array}$ & $\begin{array}{c}185.00 \\
(152.50 \\
\text { to } \\
277.50)\end{array}$ & $\begin{array}{c}-110.00 \\
(-127.00 \\
\text { to }-62.50)\end{array}$ & 0.02 & $\begin{array}{c}175.00 \\
(43.75 \text { to } \\
227.50)\end{array}$ & $\begin{array}{c}105.00 \\
(25.75 \text { to } \\
185.00)\end{array}$ & $\begin{array}{c}-17.00 \\
(-102.50 \\
\text { to }-11.00)\end{array}$ & 0.06 & $\begin{array}{c}-65.00 \\
(-130.00 \\
\text { to }-20.00)\end{array}$ & $<0.01$ \\
\hline $\mathrm{mBorg}^{+}$ & $\begin{array}{c}3.00 \\
(2.00 \text { to } \\
4.00)\end{array}$ & $\begin{array}{c}4.00 \\
(3.00 \text { to } \\
4.50)\end{array}$ & $\begin{array}{c}-1.00 \\
(-2.00 \text { to } \\
-0.50)\end{array}$ & 0.06 & $\begin{array}{c}2.50 \\
(0.88 \text { to } \\
5.25)\end{array}$ & $\begin{array}{c}1.50 \\
(0.25 \text { to } \\
5.00)\end{array}$ & $\begin{array}{c}-0.25 \\
(-0.88 \text { to } \\
0.00)\end{array}$ & 0.250 & $\begin{array}{c}-1.00 \\
(-2.00 \text { to } \\
0.00)\end{array}$ & $<0.01$ \\
\hline$\Delta \mathrm{mBorg}{ }^{\S}$ & $\begin{array}{c}3.00 \\
(1.00 \text { to } \\
3.00)\end{array}$ & $\begin{array}{c}3.00 \\
(2.50 \text { to } \\
3.50)\end{array}$ & $\begin{array}{c}-1.00 \\
(-2.00 \text { to } \\
-0.50)\end{array}$ & 0.06 & $\begin{array}{c}2.50 \\
(0.88 \text { to } \\
3.00)\end{array}$ & $\begin{array}{c}1.50 \\
(0.25 \text { to } \\
2.00)\end{array}$ & $\begin{array}{c}-0.25 \\
(-0.88 \text { to } \\
0.00)\end{array}$ & 0.25 & $\begin{array}{c}-1.00 \\
(-2.00 \text { to } \\
0.00)\end{array}$ & $<0.08$ \\
\hline \multicolumn{11}{|l|}{$\begin{array}{l}\text { Objective } \\
\text { measures of } \\
\text { physiology }\end{array}$} \\
\hline $\mathrm{HR}^{+}$ & $\begin{array}{c}89.00 \\
(84.50 \text { to } \\
99.50)\end{array}$ & $\begin{array}{c}87.00 \\
(85.00 \text { to } \\
99.50)\end{array}$ & $\begin{array}{c}0.00 \\
(-4.50 \text { to } \\
1.50)\end{array}$ & 0.69 & $\begin{array}{c}89.50 \\
(86.75 \text { to } \\
91.50)\end{array}$ & $\begin{array}{c}84.50 \\
(81.75 \text { to } \\
90.25)\end{array}$ & $\begin{array}{c}-1.50 \\
(-6.50 \text { to } \\
2.75)\end{array}$ & 0.69 & $\begin{array}{c}0.00 \\
(-6.00 \text { to } \\
2.00)\end{array}$ & 0.49 \\
\hline$\Delta H R^{\S}$ & $\begin{array}{l}10.00 \\
(5.00 \text { to } \\
15.00)\end{array}$ & $\begin{array}{c}10.00 \\
(10.00 \text { to } \\
12.00)\end{array}$ & $\begin{array}{c}0.00 \\
(-6.00 \text { to } \\
4.00)\end{array}$ & 0.88 & $\begin{array}{l}6.00 \\
(2.50 \text { to } \\
12.50)\end{array}$ & $\begin{array}{l}5.50 \\
(2.75 \text { to } \\
12.75)\end{array}$ & $\begin{array}{l}1.00 \\
(-2.00 \text { to } \\
2.50)\end{array}$ & 0.85 & $\begin{array}{c}1.00 \\
(-3.00 \text { to } \\
3.00)\end{array}$ & 0.96 \\
\hline $\mathrm{S}_{\mathrm{pO}_{2}}^{+}$ & $\begin{array}{c}94.00 \\
(92.50 \text { to } \\
95.50)\end{array}$ & $\begin{array}{c}94.00 \\
(93.00 \text { to } \\
97.00)\end{array}$ & $\begin{array}{c}0.00 \\
(-3.00 \text { to } \\
0.00)\end{array}$ & 0.25 & $\begin{array}{c}98.0 \\
(96.50 \text { to } \\
98.00)\end{array}$ & $\begin{array}{c}96.50 \\
(96.00 \text { to } \\
97.75)\end{array}$ & $\begin{array}{c}0.00 \\
(-0.75 \text { to } \\
0.00)\end{array}$ & 0.75 & $\begin{array}{c}0.00 \\
(-2.00 \text { to } \\
0.00)\end{array}$ & 0.16 \\
\hline$\Delta S_{\mathrm{pO}_{2}}^{\S}$ & $\begin{array}{c}0.00 \\
(-3.50 \text { to } \\
1.00)\end{array}$ & $\begin{array}{c}-1.00 \\
(-1.50- \\
0.50)\end{array}$ & $\begin{array}{c}-1.00 \\
(-2.50 \text { to } \\
1.50)\end{array}$ & 0.52 & $\begin{array}{c}0.50 \\
(-1.50 \text { to } \\
2.50)\end{array}$ & $\begin{array}{c}-0.50 \\
(-1.00 \text { to } \\
0.00)\end{array}$ & $\begin{array}{c}-1.00 \\
(-1.75 \text { to } \\
0.50)\end{array}$ & 0.53 & $\begin{array}{l}-1.00 \\
(-2.00 \text { to } \\
1.00)\end{array}$ & 0.29 \\
\hline
\end{tabular}

\section{Objective}

measures of

functional

response

\begin{tabular}{|c|c|c|c|c|c|c|c|c|c|c|}
\hline $\begin{array}{l}\text { 6MWT } \\
\text { distance }^{f}(\mathrm{~m})\end{array}$ & $\begin{array}{c}282.50 \\
(233.75 \\
\text { to } \\
470.25)\end{array}$ & $\begin{array}{c}265.00 \\
(209.75 \\
\text { to } \\
430.00)\end{array}$ & $\begin{array}{c}28.00 \\
(20.00 \text { to } \\
38.75)\end{array}$ & 0.06 & $\begin{array}{c}432.50 \\
(399.38 \\
\text { to } \\
516.25)\end{array}$ & $\begin{array}{c}531.30 \\
(421.25 \\
\text { to } \\
560.63)\end{array}$ & $\begin{array}{c}22.50 \\
(11.25 \text { to } \\
71.25)\end{array}$ & 0.06 & $\begin{array}{c}28.00 \\
(17.50 \text { to } \\
45.00)\end{array}$ & $<0.01$ \\
\hline $\begin{array}{l}\text { 6MWT stops } \\
\text { (n) }\end{array}$ & $\begin{array}{c}0.00 \\
(0.00 \text { to } \\
2.00)\end{array}$ & $\begin{array}{c}1.00 \\
(0.00 \text { to } \\
1.50)\end{array}$ & $\begin{array}{c}0.00(0.00 \\
\text { to } 0.00)\end{array}$ & 1.00 & $\begin{array}{c}0.00 \\
(0.00 \text { to } \\
0.00)\end{array}$ & $\begin{array}{c}0.00 \\
(0.00 \text { to } \\
0.00)\end{array}$ & $\begin{array}{c}0.00(0.00 \\
\text { to } 0.00)\end{array}$ & 1.00 & $\begin{array}{c}0.00(0.00 \\
\text { to } 0.00)\end{array}$ & 0.75 \\
\hline
\end{tabular}

Only within-individual differences in the medians (WIDiMs) are used for estimating treatment effects; group-level medians are helpful in assessing carryover and order effects (see methods section). IQR: interquartile range; NRS: numerical rating scale; $\Delta$ : change; mBorg: modified Borg scale for breathlessness; $\mathrm{HR}$ : heart rate; $\mathrm{S}_{\mathrm{pO}_{2}}$ : oxygen saturation measured by pulse oximetry. ${ }^{\#}$ : calculated so that positive values indicate higher scores for the fan condition and negative values indicate higher scores for the no-fan condition; ": exact significant, two-tailed; ${ }^{+}$: assessed post-exercise; ${ }^{\S}$ : change from pre- to post-exercise; ${ }^{f}$ : assessed during the exercise period. 
(92\%) out of the 14 patients completed the reproducibility study. One patient declined to participate in the reproducibility study due to unforeseeable personal circumstances.

\section{Patient characteristics}

14 patients with COPD completed the trial per protocol (four male, 10 female; median (IQR) age 66.50 (60.75 to 73.50) years and mMRC dyspnoea 3 (2 to 3)), summarised in table 1.

\section{Outcomes}

Prior to exercise there were no differences between the experimental conditions for resting NRS breathlessness, mBorg, heart rate or $S_{\mathrm{pO}_{2}}$. Following exercise, change scores for the primary outcome $(\triangle \mathrm{NRS})$ showed that low-level physical activity under the fan condition resulted in lower exercise-induced breathlessness, i.e. smaller increases in breathlessness compared to the no-fan condition (WIDiM -1.00 , IQR -2.00 to $-0.50 ; \mathrm{p}<0.01$ ). For the secondary outcomes, the fan condition resulted in smaller increases in perceived breathing difficulty/effort ( $\Delta$ mBorg) (WIDiM -0.25 , IQR -2.00 to $0.00 ; \mathrm{p}=0.02$ ), greater distance walked during the 6MWT (WIDiM $21.25 \mathrm{~m}$, IQR 12.75 to $31.88 \mathrm{~m}$; p<0.01), and a shorter post-exertional breathlessness recovery time (seconds) (WIDiM $-10.00 \mathrm{~s}, \mathrm{IQR}-78.75$ to $50.00 \mathrm{~s}$; p<0.01) (table 2). However, there were no overall treatment effects for heart rate, $S_{\mathrm{pO}_{2}}$ or the number of stops taken during the 6MWT.

The reproducibility crossover trial (trial 2) demonstrated consistent findings of benefits for the fan condition: smaller increases in breathlessness ( $\triangle \mathrm{NRS}$ ) (WIDiM -1.00 , IQR -1.00 to 0.00 ; $\mathrm{p}<0.01$ ), smaller increases in perceived breathing difficulty/effort $(\Delta \mathrm{mBorg})$ (WIDiM -1.00 , IQR -2.00 to 0.00 ; $\mathrm{p}<0.01$ ), greater distance walked during the 6MWT (WIDiM $28.00 \mathrm{~m}$, IQR 17.50 to $45.00 \mathrm{~m}, \mathrm{p}<0.01$ ) and a shorter post-exertional breathlessness recovery time (seconds) (WIDiM $-65.00 \mathrm{~s}, \mathrm{IQR}-130.00$ to $-20.00 \mathrm{~s} ; \mathrm{p}<0.01$ ) (table 3). Again, there were no overall treatment effects for heart rate, $S_{\mathrm{pO}_{2}}$ or the number of stops taken during the 6MWT.

Fan therapy was acceptable to 92\% of participants (table 4), with a median (IQR) acceptability score of 4 (4 to 5) out of 5. 53\% reported no additional burden of fan therapy during the 6MWT. Patients reported they liked the handheld fan (median 4, IQR 3 to 5) and that it was of minimal burden (median 1, IQR 1 to 3 ). Patients were confident to use the handheld fan (median 5, IQR 4 to 5) and understood how it was supposed to help them (median 4, IQR 3 to 5).

In keeping with the observed improvements in breathlessness scores and exercise performance, patients perceived the handheld fan to be effective during exercise (median 4, IQR 3 to 4) and to help to resolve breathlessness post-exertion (median 4, IQR 3 to 4). Moreover, these patients who had not used a fan

\section{TABLE 4 Patient-reported acceptability of hand-held fan (HHF) therapy during exercise}

$$
\text { Question }
$$

Median Range

(IQR)

(min-max)

\begin{tabular}{|c|c|c|c|}
\hline Overall acceptability & $\begin{array}{l}\text { How acceptable was it to use the HHF during the exercise test? } \\
\text { (1=completely unacceptable, } 5=\text { =completely acceptable) }\end{array}$ & $4(4-5)$ & $3-5$ \\
\hline Affective attitude & $\begin{array}{l}\text { How much did you like using the HHF during the walking test? } \\
\text { (1=strongly dislike, } 5=\text { strongly like) }\end{array}$ & $4(3-5)$ & $3-5$ \\
\hline Burden & $\begin{array}{l}\text { How much additional effort was required to use the HHF during the walking test? } \\
\qquad(1=\text { no additional effort, } 5=\text { a huge additional effort) }\end{array}$ & $1(1-3)$ & $1-4$ \\
\hline Self-efficacy & $\begin{array}{l}\text { How confident were you about using the HHF as instructed during the walking test? } \\
\text { (1=very unconfident, } 5=\text { =very confident) }\end{array}$ & $5(4-5)$ & $1-5$ \\
\hline $\begin{array}{l}\text { Intervention } \\
\text { coherence }\end{array}$ & $\begin{array}{l}\text { Do you understand how the HHF therapy was supposed to work? } \\
\text { (1=definitely do not understand, } 5=\text { =completely understand) }\end{array}$ & $4(3-5)$ & $2-5$ \\
\hline \multirow[t]{3}{*}{$\begin{array}{l}\text { Perceived } \\
\text { effectiveness }\end{array}$} & $\begin{array}{l}\text { How effective was the HHF in reducing breathlessness when walking? } \\
\text { (1=very ineffective, } 5=\text { =very effective) }\end{array}$ & $4(3-4)$ & $3-5$ \\
\hline & $\begin{array}{l}\text { How effective was the HHF therapy in helping you to recover your breathing after you } \\
\text { finished walking? } \\
\text { (1=very ineffective, } 5=\text { very effective) }\end{array}$ & $4(3-4)$ & $3-5$ \\
\hline & $\begin{array}{l}\text { Would you use a HHF to help with breathlessness in your everyday life? } \\
\text { ( } 1=\text { I definitely would not use it, } 5=1 \text { definitely would use it) }\end{array}$ & $5(4-5)$ & $2-5$ \\
\hline
\end{tabular}


before reported that they would use a handheld fan during everyday life (median 5, IQR 4 to 5), which reinforces the acceptability of this intervention. One person commented that using (holding) the fan negatively affected their walking style. Free-text comments were limited, but supported the use of the handheld fan:

“very useful during exercising” (male, FEV $V_{1} 0.59 \mathrm{~L}$ )

"I think it worked... it helped my breathing” (female, FEV $1.40 \mathrm{~L}$ )

"it acts as a distraction from my breathing, which I find useful” (female, FEV 1.55 L)

\section{Discussion}

This study aimed to investigate the effect of fan therapy on exercise-induced breathlessness and post-exercise recovery time in patients with COPD, and the acceptability of using fan therapy during exercise in controlled circumstances. Findings across two pilot crossover trials with the same participants suggest that using a hand-held fan during low-level exercise has no impact on physiological measures (heart rate, $S_{\mathrm{pO}_{2}}$ ), but reduces subjective feelings of exercise-induced breathlessness, increases walking distance and speeds post-exertional recovery time. Fan therapy was deemed to be acceptable by $92 \%$ of participants.

This is the first article to report an improvement in recovery time post-exertion due to fan therapy in patients with COPD. The reduction in exercise-induced breathlessness was similar to that described by MarchetTi et al. [21], who reported significance between median (range) mBorg at maximal exercise of 6.50 (0 to 10 ) with fan directed to leg versus 5.00 ( 0 to 10$)$ with fan directed to face $(p=0.03)$. Our data extend these findings and show that using a handheld fan during exercise was perceived to be acceptable to participants and provided symptomatic relief to patients with COPD during exercise. These data will inform larger efficacy studies of fan therapy during exercise.

\section{Relevance of findings}

The UK MRC produced a series of guidelines from 2000 onwards to help researchers develop and evaluate of complex health interventions. These MRC guidelines explicitly recommend that developers assess the acceptability of prototype interventions at an early stage and throughout the development process [22-24]. There is now a growing consensus that developers need to optimise interventions to ensure acceptability to those delivering and receiving them [25]. Evidence shows that the acceptability of interventions impacts on their implementation, uptake, adherence and effectiveness [24, 26-28]. The TFA [18] identifies underlying constructs presumed to contribute to evaluations of intervention acceptability and offers suggestions on how to assess acceptability. The current study used the TFA to guide the assessment of the retrospective acceptability of fan therapy to intervention recipients. The findings provide preliminary support for the acceptability of the fan therapy to patients with COPD, suggesting not only that fan therapy was acceptable overall, but that the intervention required low effort, was liked and participants understood how the fan was supposed to help them during exertion. Participants were confident as how to use the fan as directed. Participants perceived the fan to be effective at reducing breathlessness, helping them return to normal breathing post-exertion, and that it would be useful during everyday tasks (table 4). This is in line with the observation by BAUSEWEIN et al. [29] that at 2 months post-completion, 50\% of participants continued to use the fan. Findings relating to acceptability were positive for all TFA constructs assessed, suggesting that there is no need adapt the intervention prior to further evaluation. However, acceptability can change with exposure to an intervention; therefore, future studies should assess the acceptability of fan therapy for people with COPD and other respiratory conditions at multiple time points during longer exposures. Furthermore, studies should use the full range of TFA constructs (we did not assess the perceived opportunity costs or ethics of fan therapy) and assess acceptability of fan therapy to intervention deliverers.

In keeping with our observations, JoHnson et al. [30] used magnetoencephalography to scan the brains of participants $(n=8)$ with chronic lung disease (50\% diagnosed with COPD) during post-exertional recovery following exercise with or without airflow. Time recovery was median $270 \mathrm{~s}$ (range 60 to $360 \mathrm{~s}$ ) with airflow versus $330 \mathrm{~s}$ (range 210-390 s), which is longer than in our cohort, indicating that our sample recovered quicker, although our sample did not achieve such a high breathlessness intensity. Preliminary imaging suggested that facial airflow might result in different areas of lobar activity being identified, potentially altering central processing and perception of neural respiratory drive and breathlessness. The insular cortex, anterior cingulate cortex and amygdala contribute towards this [31]. 
Brain imaging in healthy participants suggest that affective experiences (e.g. distress, anxiety, fear) and the sensory experiences (e.g. pain, difficulty breathing) of breathlessness are processed by different neural pathways [32].

Physiological studies in healthy volunteers propose that cool air stimulates facial receptors connected to the trigeminal nerve, altering input to sensory processing areas of the brain [33], while oral mucosal stimulation can affect afferent information [34], thereby altering and reducing the perception and intensity of breathlessness. MoréLot-PAnzini [35] describes this as "fooling the brain" into the perception that the respiratory system is more efficient than it is. These physiological observations are supported by qualitative accounts of patients' coping strategies used to manage acute breathlessness e.g. opening windows, letting cold air into the room [36].

LANSING et al. [37] proposed a multidimensional model of dyspnoea based on the pain literature, where unpleasant sensations of breathlessness lead to withdrawal from physical activity, while an emotional component then leads to lifestyle changes to avoid dyspnoea. Avoiding dyspnoea triggers, such as physical activity, results in deconditioning, which lowers the threshold for dyspnoea and causes further decline.

Patients with COPD frequently feel helpless or not in control of their breathlessness, which is distressing for both the patient and their significant others [36, 38]. This can lead to them avoiding activities that make them breathless. An intervention that could reduce the extent of exertion-induced breathlessness and improve the recovery time could be important in breaking the cycle of avoidance behaviours commonly seen in patients with COPD and potentially lead to improvements in health-related quality of life.

Significant differences in favour of fan therapy were observed for two measures of breathlessness (NRS and mBorg) and distance on the 6MWT (tables 2 and 3). Based on the overall treatment effect, NRS scores were 1 unit lower in the fan condition (trial 1 and trial 2); mBorg scores were between 0.25 units (trial 1) and 1 unit (trial 2) lower in the fan condition; and distance walked was between $21 \mathrm{~m}$ (trial 1) and $28 \mathrm{~m}$ (trials 2) greater in the fan condition. Of these outcomes, only the NRS demonstrated consistent benefits (across both trials) for the fan condition which reached the respective MCID (1 unit for NRS) [39].

Benefits of the fan condition as assessed by mBorg breathlessness and distance on the 6MWT failed to consistently meet the MCIDs of 1 unit and $30 \mathrm{~m}$ [17, 19, 39]. Nevertheless, the findings for NRS suggest that the use of a fan during low-level physical activity may lead to clinically meaningful improvements in breathlessness and functional response. However, these improvements need to be contextualised as they were observed in a controlled situation on a flat indoor surface and were transitory. Taken at face value, the findings suggest there could be a role for fan therapy in helping individuals with COPD to cope with physical exertion (e.g. walking upstairs) or participation in patient exercise/rehabilitation programmes.

All outcomes were assessed over a very short period of time, and we cannot comment on the longer-term potential benefits of fan therapy. Future studies need to validate these acute findings and look at the acceptability and feasibility of sustained use of fan therapy and potential long-term benefits. Different roles for fan therapy should also be explored. For example, fans can be used for temporary symptomatic relief during day-to-day activities or in a more therapeutic way as an adjunct to exercise interventions and/or breathlessness self-management interventions; both approaches may be useful. Studies should explore benefits across a wider range of patient-reported outcomes such as breathlessness mastery, health-related quality of life and illness perception, as these are potentially modifiable factors.

We report some positive preliminary findings, along with some null results that suggest fan therapy merits further investigation in larger and more methodologically rigorous studies. The current study raises important practical considerations such as how will people use handheld fans in their day-to-day life (is it just an aid while they try to improve their respiratory fitness on a treadmill, or would they find it useful while walking to the park/shop/friend's house?). There is also a question of whether people will use a fan on an ongoing basis, either as a rehabilitation aid or as a practical day-to-day aid for going to shops, etc. Does the use of a fan translate into quality-of-life benefits? The low cost and scalability of fan therapy could increase the potential impact, although the real-world practicalities of fan therapy should be examined.

\section{Strengths and limitations}

A strength of the study was the use of a practice walk with the 6MWT. There is known learning effect with the 6MWT, with the second test usually performing better [17]. 
Internal validity was enhanced by a randomised crossover study design, which is suitable in chronic disease for evaluating the temporary effect of an intervention [40].

This study achieved a 53.8\% recruitment rate from screening, similar to previous breathlessness literature [41]. This suggests that the generalisability of the current findings may be limited to only those people willing to engage with the intervention. Future studies could usefully embed an assessment of the reasons for refusal to participate, as has been done in other challenging clinical areas, e.g. occupational therapy intervention for individuals with dementia [42].

We must acknowledge the potential fatigue impact of undertaking three 6MWTs in a day. We ensured that there was sufficient time between walk tests and that patients remained at their symptomatic baseline prior to each test. However, we did not account for the potential effect of fatigue on the observed outcomes, a point that warrants consideration when planning subsequent trials.

Washout periods aim to reduce the potential of carryover effects of the intervention being studied. There is no consensus on the optimal duration of washout periods. Pharmacological studies often calculate their washout period based on five or more times the half-life of the drug under investigation [43]. For nonpharmacological interventions, deciding the optimal duration of the washout period is challenging. Galbraith et al. [44] reported that a 10-min washout after use of hand-held fan therapy at rest was insufficient. In this study, we choose a 30 -min washout period as we believe that this would provide sufficient time for patients to physiologically recover from the 6MWT and for the acute potential effects of the fan therapy to have diminished. It must be acknowledged that a longer washout period of an hour may be more appropriate in subsequent studies, especially if including patients with advanced disease (mMRC $>3$ ). Moreover, it is important to factor in the overall time burden of the study design on participants, an important factor when estimating recruitment rates.

Commercially purchased, pocket-sized travel fans were used [41]; however, a limitation of this and most other fan therapy literature is that the that airflow generated by each fan used (either static or hand-held) appears to be generally unknown. MARсhEтTI et al. [21] reported that the peak airflow generated by their static fan was $840 \mathrm{ft} \cdot \mathrm{min}^{-1}$. Airflow studies describe a range of flow rates. What remains to be ascertained is whether there is a minimal or optimum flow rate that should be used in these studies to allow for greater comparison and transparency of results.

\section{Conclusion}

Fan therapy using a low-cost, readily available hand-held fan was acceptable and provided symptomatic relief to patients with COPD during a short period of low-level exercise (walking). Our positive preliminary findings suggest that fan therapy merits further investigation in larger and more methodologically rigorous studies. The current study raises important practical considerations such as (how) would people use handheld fans in their day-to-day life

Acknowledgement: This report is independent research supported by the National Institute for Health Research (NIHR) (MRes studentship at City, University of London, to A. Long). This study represents independent research supported by the NIHR. An NIHR Clinical Lectureship (ICA-CL-2018-04-ST2-001) supports C.C. Reilly. The views expressed in this publication are those of the authors and not necessarily those of the National Health Service, the NIHR or the Dept of Health and Social Care.

Provenance: Submitted article, peer reviewed.

Data availability: Data will not be shared

Author contributions: Conception and design: C.C. Reilly. Data acquisition: A. Long. Statistical analysis and interpretation: M. Cartwright. Drafting the manuscript for important intellectual content: A. Long and C.C. Reilly. Final review of manuscript: all authors.

Conflict of interest: None declared.

\section{References}

1 Global Initiative for Chronic Obstructive Lung Disease (GOLD). Global Strategy for the Diagnosis, Management and Prevention of COPD. 2017. Available from: http://goldcopd.org/ 
2 Lozano R, Naghavi M, Foreman K, et al. Global and regional mortality from 235 causes of death for 20 age groups in 1990 and 2010: a systematic analysis for the Global Burden of Disease Study 2010. The Lancet 2012; 380: 2095-2128.

3 British Lung Foundation. Chronic Obstructive Pulmonary Disease (COPD) Statistics. 2020. https://statistics.blf. org.uk/COPD/.

4 Jolley CJ, Moxham J. A physiological model of patient-reported breathlessness during daily activities in COPD. Eur Respir Rev 2009; 18: 66-79.

5 O'Donnell DE, James MD, Milne KM, et al. The pathophysiology of dyspnea and exercise intolerance in chronic obstructive pulmonary disease. Clin Chest Med 2019; 40: 343-366.

6 Seymour JM, Moore L, Jolley CJ, et al. Outpatient pulmonary rehabilitation following acute exacerbations of COPD. Thorax 2010; 65: 423-428.

7 Man WD-C, Soliman MGG, Gearing J, et al. Symptoms and quadriceps fatigability after walking and cycling in chronic obstructive pulmonary disease. Am J Respir Crit Care Med 2003; 168: 562-567.

8 Swan F, Booth S. The role of airflow for the relief of chronic refractory breathlessness. Curr Opin Support Palliat Care 2015; 9: 206-211.

9 Booth S, Galbraith S, Ryan R, et al. The importance of the feasibility study: lessons from a study of the hand-held fan used to relieve dyspnea in people who are breathless at rest. Palliat Med 2016; 30: 504-509.

10 Gysels MH, Higginson IJ. The lived experience of breathlessness and its implications for care: a qualitative comparison in cancer, COPD, heart failure and MND. BMC Palliat Care 2011; 10; 15.

11 Hutchinson A, Pickering A, Williams P, et al. Breathlessness and presentation to the emergency department: a survey and clinical record review. BMC Pulm Med 2017; 17: 53.

12 Brighton LJ, Miller S, Farquhar M, et al. Holistic services for people with advance disease and chronic breathlessness: a systematic review and meta-analysis. Thorax 2019; 74: 270-281.

13 Smallwood N, Thompson M, Warrender-Sparkes M, et al. Integrated respiratory and palliative care may improve outcomes in advanced lung disease. ERJ Open Res 2018; 4: 00102-2017.

14 Johnson MJ, Currow DC, Booth S. Prevalence and assessment of breathlessness in the clinical setting. Expert Rev Respir Med 2014; 8: 151-161.

15 Borg GA. Psychophysical bases of perceived exertion. Med Sci Sports Exerc 1982; 14: 377-381.

16 Ries AL. Minimally clinically important difference for the UCSD Shortness of Breath Questionnaire, Borg scale, and visual analog scale. COPD 2005; 2: 105-110.

17 Singh SJ, Puhan MA, Andrianopoulos V, et al. An official systematic review of the European Respiratory Society/American Thoracic Society: measurement properties of field walking tests in chronic respiratory disease. Eur Respir J 2014; 44: 1447-1478.

18 Sekhon M, Cartwright M, Francis JJ. Acceptability of healthcare interventions: an overview of reviews and development of a theoretical framework. BMC Health Serv Res 2017; 17: 88.

19 Holland AE, Spruit MA, Troosters T, et al. An official European Respiratory Society/American Thoracic Society technical standard: field walking tests in chronic respiratory disease. Eur Respir J 2014; 44: 1428-1446.

20 Li T, Yu T, Hawkins BS, et al. Design, analysis, and reporting of crossover trials for inclusion in a meta-analysis. PLoS One 2015; 10: e0133023.

21 Marchetti N, Lammi MR, Travaline JM, et al. Air current applied to the face improves exercise performance in patients with COPD. Lung 2015; 193: 725-731.

22 Campbell M, Fitzpatrick R, Haines A, et al. Framework for design and evaluation of complex interventions to improve health. BMJ 2000; 321: 694-696. .

23 Craig P, Dieppe P, Macintyre S, et al. Developing and evaluating complex interventions: the new Medical Research Council guidance. BMJ 2008; 337: a1655.

24 Moore GF, Audrey S, Barker M, et al. Process evaluation of complex interventions: Medical Research Council guidance. BMJ 2015; 350: h1258.

25 O'Cathain A, Croot L, Duncan E, et al. Guidance on how to develop complex interventions to improve health and healthcare. BMJ Open 2019; 9: e029954. .

26 Haynes B. Can it work? Does it work? Is it worth it? The testing of healthcare interventions is evolving. BMJ 1999; 319: 652-653.

27 Say RE, Thomson R. The importance of patient preferences in treatment decisions - challenges for doctors. BMJ 2003; 327: 542-545.

28 Sidani S, Braden CJ. Testing the acceptability and feasibility of interventions. In: Design, Evaluation, and Translation of Nursing Interventions. Chichester, John Wiley \& Sons, 2011; pp. 163-196.

29 Bausewein C, Booth S, Gysels M, et al. Effectiveness of a hand-held fan for breathlessness: a randomised phase II trial. BMC Palliat Care 2010; 9: 22.

30 Johnson MJ, Simpson MI, Currow DC, et al. Magnetoencephalography to investigate central perception of exercise-induced breathlessness in people with chronic lung disease: a feasibility pilot. BMJ Open 2015; 5 : e007535. 
31 Pattinson KTS, Johnson MJ. Neuroimaging of central breathlessness mechanisms. Curr Opin Support Palliat Care 2014; 8: 225-233.

32 von Leupoldt A, Sommer T, Kegat S, et al. The unpleasantness of perceived dyspnea is processed in the anterior insula and amygdala. Am J Respir Crit Care Med 2008; 177: 1026-1032.

33 Schwartzstein RM, Lahive K, Pope A, et al. Cold facial stimulation reduces breathlessness induced in normal subjects. Am Rev Respir Dis 1987; 136: 58-61.

34 Simon PM, Basner RC, Weinberger SE, et al. Oral mucosal stimulation modulates intensity of breathlessness induced in normal subjects. Am Rev Respir Dis 1991; 144: 419-422.

35 Morélot-Panzini C. Fooling the brain to alleviate dyspnoea. Eur Respir J 2017; 50: 1701383.

36 Chin C, Booth S. Managing breathlessness: a palliative care approach. Postgrad Med J 2016; 92: 393-400.

37 Lansing RW, Gracely RH, Banzett RB. The multiple dimensions of dyspnea: review and hypotheses. Respir Physiol Neurobiol 2009; 167: 53-60.

38 Gysels M, Reilly CC, Jolley CJ, et al. How does a new breathlessness support service affect patients? Eur Respir J 2015; 46: 1515-1518.

39 Oxberry SG, Bland JM, Clark AL, et al. Minimally clinically important difference in chronic breathlessness: every little helps. Am Heart J 2012; 164: 229-235.

40 Elbourne DR, Altman DG, Higgins JPT, et al. Meta-analyses involving cross-over trials: methodological issues. Int J Epidemiol 2002; 31: 140-149.

41 Higginson IJ, Bausewein C, Reilly CC, et al. An integrated palliative and respiratory care service for patients with advanced disease and refractory breathlessness: a randomised controlled trial. Lancet Respir Med 2014 2: 979-987.

42 Mundy J, Stansfeld J, Orrell M, et al. Reasons for nonparticipation in the Valuing Active Life in Dementia randomised controlled trial of a dyadic occupational therapy intervention: an interview study. SAGE Open Med 2020; 8: 2050312120958926.

43 Grabowski T, Gad SC, Jaroszewki JJ, et al. Deterministic chaos and wash-out determination in crossover trials. Int J Pharmacokinet 2016; 1: 43-53.

44 Galbraith S, Fagan P, Perkins P, et al. Does the use of a handheld fan improve chronic dyspnea? A randomized, controlled, crossover trial. J Pain Symptom Manage 2010; 39: 831-838. 